\title{
Analysis of perimeter recombination in the subcells of GalnP/GaAs/Ge triple-junction solar cells
}

\author{
P. Espinet-González , I. Rey-Stolle, M. Ochoa, C. Algora, I. García and E. Barrigón
}

\begin{abstract}
This paper studies the recombination at the perimeter in the subcells that constitute a GaInP/GaAs/Ge lattice-matched triple-junction solar cell. For that, diodes of different sizes and consequently different perimeter/area ratios have been manufactured in single-junction solar cells resembling the subcells in a triple-junction solar cell. It has been found that neither in GaInP nor in Ge solar cells the recombination at the perimeter is significant in devices as small as $500 \mu \mathrm{m} \times$ $500 \mu \mathrm{m}\left(2.5 \cdot 10^{-3} \mathrm{~cm}^{2}\right)$ in GaInP and $250 \mu \mathrm{m} \times 250 \mu \mathrm{m}\left(6.25 \cdot 10^{-4} \mathrm{~cm}^{2}\right)$ in Ge. However, in GaAs, the recombination at the perimeter is not negligible at low voltages even in devices as large as $1 \mathrm{~cm}^{2}$, and it is the main limiting recombination factor in the open circuit voltage even at high concentrations in solar cells of $250 \mu \mathrm{m} \times 250 \mu \mathrm{m}\left(6.25 \cdot 10^{-4} \mathrm{~cm}^{2}\right)$ or smaller. Therefore, the recombination at the perimeter in GaAs should be taken into account when optimizing triple-junction solar cells. Copyright (C) 2014 John Wiley \& Sons, Ltd.
\end{abstract}

\section{KEYWORDS}

perimeter; recombination; CPV; concentration; multijunction; solar cells; photovoltaics

\section{INTRODUCTION}

Concentrator multijunction solar cells are very expensive devices that can only be affordable for terrestrial application when having a very high efficiency and work at high concentrations [1]. Nowadays, the record efficiency is $44.4 \%$ at about $300 \mathrm{x}$ [2] in a triple-junction solar cell (3JSC), and there is a tendency to work at higher concentrations (around $1000 \mathrm{x}$ ) that allows to manufacture smaller solar cells. In order to keep increasing the multijunction solar cell efficiency, it is a requirement to optimize not only the semiconductor structure but also the design of the device (size, front grid, etc.) taking into account the whole concentrator photovoltaic system. In this sense, in order to approach the maximum theoretical efficiency, we should try to minimize the recombination currents that are not radiative. Then, we need to know which are the main recombination mechanisms in the different subcells that makeup a multijunction solar cell in order to determine our margin of improvement and focus our efforts. Taking into account that commercial concentrator solar cells are very small with sizes typically ranging from $3.6 \cdot 10^{-3} \mathrm{~cm}^{2}$ [3] to $1 \mathrm{~cm}^{2}$, the recombination at the perimeter could be significant (specially in the smallest ones). Furthermore, determining the significance of the recombination at the perimeter could also be relevant in terms of reliability as accelerated life tests showed the important contribution of the perimeter to the degradation mechanisms in GaAs concentrator solar cells [4]. However, up to now, perimeter recombination has not been extensively studied in multijunction devices. Reinhardt et al. studied in [5] the recombination at the perimeter in $\mathrm{GaInP}$ singlejunction solar cells (SJSC) for space applications with a structure quite different to the optimum design in a concentrator multijunction solar cell. The recombination at the perimeter in GaAs SJSCs has been extensively studied in $[6,7]$, and [8] but mainly in p-type emitter and n-type base solar cells. Finally, as far as we know, there is no data in the literature about recombination at the perimeter in Ge SJSCs. 
In this paper, we analyze the impact of the recombination at the perimeter in the three subcells that makeup a $\mathrm{GaInP} / \mathrm{GaAs} / \mathrm{Ge}$ lattice-matched 3JSC. It has to be pointed out that nowadays there are seven different 3 JSC architectures with efficiencies greater than $40 \%$ [9], and all of them include a GaInP and a $\mathrm{Ga}(\mathrm{In}) \mathrm{As}$ subcell, but some of these architectures do not use a Ge bottom subcell. However, when designing four or more junctions, apart from maintaining the GaInP and $\mathrm{Ga}(\mathrm{In}) \mathrm{As}$ subcells, typically, a Ge junction is also included as a bottom cell.

In order to carry out the study of the recombination at the perimeter, diodes of different sizes and consequently different perimeter/area (P/A) ratios have been manufactured. Then, the influence of the perimeter recombination in GaInP, GaAs, and Ge diodes has been determined from the dark $I-V$ curves of diodes with different P/A ratios.

\section{THEORETICAL BACKGROUND}

In order to better follow the analysis of the recombination at the perimeter in the different diodes, a review of the relationship of the different recombination currents with the bias voltage is presented.

The dark $I-V$ curve of a SJSC can be defined as the sum of the recombination currents that take place in the different regions of the solar cell. Assuming that the recombination at the contacts is negligible because of the presence of barrier layers (window and back surface field), we can focus our analysis on the recombination in the other regions: neutral regions, depletion region, and perimeter. Therefore:

$$
I(V)=I_{N R}(V)+I_{D R}(V)+K_{P}(V) \cdot P
$$

where $I_{N R}$ is the recombination current in the neutral regions, $I_{D R}$ is the recombination current in the depletion region, $K_{P}$ is the linear recombination current density at the perimeter of the solar cell, and $P$ is the perimeter of the solar cell.

\subsection{Recombination current in the neutral regions}

The recombination in the neutral region can be described with the following expression [10]:

$$
I_{N R}(V)=I_{01}(V) \cdot\left(e^{\frac{q V}{n k T}}-1\right)
$$

where $I_{01}$ is the reverse saturation current in the neutral regions, $\mathrm{n}$ is the ideality factor, and the rest of the parameters have their standard meaning.

The main dependence of the recombination current in the neutral regions on the applied voltage $(V)$ is given by the dependence with the voltage of the injection of minority carriers from the depletion region into the neutral region (exponential dependence). Therefore, the ideality factor $(n)$ in the expression (2) is always 1 regardless of the predominant recombination mechanism in the neutral regions radiative, Shockley-Read-Hall (SRH) or Auger.

\subsection{Recombination current in the depletion region}

The recombination current in the depletion region is obtained by integrating the different recombination mechanisms (SRH, radiative, and Auger) rates along it. Therefore, it can be described with the following expression:

$I_{D R}=I_{02 S R H} \cdot e^{\frac{q V}{n_{S R H} k T}}+I_{0 R a d} \cdot e^{\frac{q V}{n_{R a d} k T}}+I_{0 A \text { Ager }} \cdot e^{\frac{q V}{n_{\text {Auger }} k T}}$

where $I_{02 S R H}$ and $n_{S R H}$ are the saturation current and the ideality factor due to $\mathrm{SRH}$ recombination, $I_{0 \mathrm{Rad}}$ and $n_{\text {Rad }}$ are the saturation current and the ideality factor due to radiative recombination, $I_{0 A u g e r}$ and $n_{\text {Auger }}$ are the saturation current and the ideality factor due to Auger recombination and the rest of the parameters with their standard meaning.

Usually, only the SRH recombination mechanism is considered in this region in the literature [10] because at forward bias capture processes are the major recombination-generation phenomena in the depletion region [11]. When the $\mathrm{SRH}$ recombination in the depletion region takes place through a single-level trap, assuming that the trap is located in the center of the band gap and the capture cross-section of electrons and holes are equal $\left(\sigma_{n}=\sigma_{p}\right)$, the maximum value of the recombination occurs where the electron and hole densities are equal. Therefore, in this case, the ideality factor $n_{S R H}$ is 2 .

On the other hand, the recombination current in the depletion regions due to radiative recombination has an ideality factor $\left(n_{R a d}\right)$ of 1 . Finally, the recombination current due to Auger recombination, assuming that the Auger recombination coefficients for electrons and holes are identical $\left(\Lambda_{n}=\Lambda_{p}\right)$, at the point where the electron and hole densities are equal, results in a ideality factor $\left(n_{\text {Auger }}\right)$ of $2 / 3$.

Therefore, unlike in the neutral regions, in the depletion region, the value of the ideality factor could vary largely depending on the characteristics of the dominating recombination process.

\subsection{Recombination current at the perimeter}

The recombination at the perimeter is due to surface states that generally introduce a continuum of traps lying in the forbidden gap between the conduction band and the valence band. They are originated either by the dangling bonds at the semiconductor surface due to the abrupt interruption of the crystal lattice or by the adsorption of impurities on the perimeter surface [7]. The interaction of carriers (mainly minority) with surface traps influences the 
distribution of the potential barrier at the perimeter surface that is smaller than the built-in potential at the bulk, so the potential barrier to be surpassed by carriers at the $\mathrm{p}-\mathrm{n}$ junction will be lower at the perimeter surface than in the bulk region (away from the surface) [12]. The band bending at the perimeter surface created by the surface states causes the formation of the so-called 'surface channel' that is a region where the minority carriers are confined. Therefore, once a channel is formed, it gives rise to surface leakage [11].

At low bias, the region of the perimeter with the higher recombination rate occurs mainly in the intersection with the depletion region $([12,13])$. By increasing the forward bias, the voltage applied reduces the built-in potential in the bulk and along the surface at the perimeter. Therefore, in the neutral regions (at the vicinity of the depletion region) at the perimeter surface and in the bulk, the recombination rate begins to increase because all the traps inside the depletion region are ionized, so the minority carriers begin to occupy bulk and perimeter trap states outside the space charge region. Then, the contribution of the recombination in the neutral regions is more significant as the bias voltage is increased. Hence, although at high bias, the surface channel still acts as a sink of carriers, the difference between bulk and perimeter recombination values decreases. This reduction is enough to make the integration of recombination rate in bulk regions greater than the one at the perimeter [12].

Therefore, in a first approximation, the recombination current at the perimeter could be divided into the contribution of the recombination at the perimeter at low bias voltages (mainly in the depletion region) and at moderate and high bias voltages (when the recombination at the perimeter extends towards the neutral regions).

$$
K_{P}=K_{P D R}+K_{P N R}
$$

where $K_{P D R}$ is the linear recombination current density at the perimeter in the intersection with the depletion region (which is more significant at low bias voltages) and $K_{P N R}$ is the linear recombination current density at the perimeter in the intersection with the neutral regions (which takes place at moderate and high voltages). Accordingly,

$$
\begin{aligned}
& K_{P D R}=K_{02 P} \cdot e^{\left(\frac{q V}{n P D R k T}\right)} \\
& K_{P N R}=K_{01 P} \cdot e^{\left(\frac{q V}{n P N R k T}\right)}
\end{aligned}
$$

where $K_{02 P}$ and $K_{01 P}$ are the saturation current densities of the recombination at the perimeter in the intersection with the depletion region and the neutral regions, respectively. $n_{P D R}$ is the ideality factor of the recombination at the perimeter in the intersection with the depletion region, its value depends on the position of the traps at the surface, their capture section, density, and so on. In GaAs, it has been experimentally reported to have a value ranging from 1.8 to $2[12,13]$. Finally, $n_{P N R}$ is the ideality factor of the recombination at the perimeter in the intersection with the neutral regions, and its value is 1 $\leq n_{P N R} \leq n_{P D R}[12]$.

\section{EXPERIMENTAL}

In an ideal case, the best way to realize the electrical characterization of a 3JSC would be to have individual access to each subcell in the stack. Unfortunately, this is not possible for the typical two-terminal monolithic configuration. Therefore, in this work, the impact of the recombination at the perimeter in SISCs resembling those of each junction in a 3JSC is studied. For that, GaInP, $\mathrm{GaAs}$, and Ge SJSCs have been grown by low pressure metal-organic vapor-phase epitaxy. The specific characteristics (material, doping level, and thickness) of each layer in the SJSCs studied are presented in their corresponding sections.

Once the semiconductor structures had been grown, they were processed using conventional techniques involving optical photolithography and thermal evaporation plus contact alloy in order to achieve diodes with their front and back sides completely covered with metal. In this way, the lateral series resistance effect introduced by grid patterns and lateral flow of current in the emitter are avoided. To evaluate the perimeter and bulk components of the dark $I-V$ curves of the devices, special photomasks were designed with diodes of different P/A ratios. The geometrical characteristics of diodes manufactured using these photomasks are presented in Table I.

Finally, regarding the measurements of the dark $I-V$ curves carried out in this study, a conventional Keithley 2420 source meter has been used. The diodes were measured in a probe station employing the four-wire technique. The probe station incorporates a Peltier system to control the temperature of the diodes in order to prevent voltage variations due to heating.

Once the dark $I-V$ curves of diodes of different sizes have been measured, the current density $(\mathrm{J})$ versus voltage

Table I. Characteristics of the square diodes manufactured.

\begin{tabular}{lccc}
\hline Side, $t(\mathrm{~cm})$ & $\begin{array}{c}\text { Perimeter, } P \\
(\mathrm{~cm})\end{array}$ & $\begin{array}{c}\text { Area, A } \\
\left(\mathrm{cm}^{2}\right)\end{array}$ & $\begin{array}{c}\text { P/A } \\
\left(\mathrm{cm}^{-1}\right)\end{array}$ \\
\hline 1.0000 & 4.0 & 1.00 & 4.0 \\
0.4000 & 1.6 & 0.16 & 10.0 \\
0.2000 & 0.8 & 0.04 & 20.0 \\
0.1000 & 0.4 & 0.01 & 40.0 \\
0.0750 & 0.3 & $5.63 \cdot 10^{-3}$ & 53.3 \\
0.0500 & 0.2 & $2.50 \cdot 10^{-3}$ & 80.0 \\
0.0250 & 0.1 & $6.25 \cdot 10^{-4}$ & 160 \\
\hline
\end{tabular}

$\mathrm{P} / \mathrm{A}$, perimeter/area. 
(V) and linear current density $(\mathrm{K})$ versus voltage have been represented. The current density is the current divided by the area $(\mathrm{J}=\mathrm{I} / \mathrm{A})$, and the linear current density is the current divided by the perimeter $(\mathrm{K}=\mathrm{I} / \mathrm{P})$.

\section{ANALYSIS OF PERIMETER RECOMBINATION}

The current recombination in the neutral regions $\left(I_{N R}\right)$ and in the depletion region $\left(I_{D R}\right)$ takes place in the bulk of the semiconductor, and consequently, these recombination mechanisms are area dependent and not perimeter dependent. On the contrary, the recombination at the perimeter surface is obviously perimeter dependent and not area dependent. Then, by measuring the dark $I-V$ curves of diodes of different areas and perimeters, we are able to discern if the main recombination at different voltages takes place at the surface of the perimeter or in the bulk of the semiconductor.

\subsection{GalnP}

The semiconductor structure of the GaInP SJSCs grown for this study is presented in Table II. Once the GaInP structures have been grown, diodes with sizes ranging from $1000 \mu \mathrm{m} \times 1000 \mu \mathrm{m}\left(0.01 \mathrm{~cm}^{2}, \mathrm{P} / \mathrm{A}=40\right)$ to $250 \mu \mathrm{m} \times$ $250 \mu \mathrm{m}\left(6.25 \cdot 10^{-4} \mathrm{~cm}^{2}, \mathrm{P} / \mathrm{A}=160\right) \quad($ Table I) were manufactured.

In Figure 1, representative curves of diodes of different sizes are depicted. We observe that none of the $J-V$ curves of the diodes of different sizes presents an ideality factor of 1 at any of the voltages. In fact, these particular diodes at moderate currents (higher than $4 \cdot 10^{-6} \mathrm{~A}$ ) present an ideality factor around 1.3. According to the theory presented in Section 2 an ideality factor higher than 1 could be due to recombination in the depletion region or recombination at the perimeter.

In Figure 1, a dependence with the area is clearly observed for the whole curve, that is, the $J-V$ curves of diodes with different size overlap (until voltages higher than $1.6 \mathrm{~V}$ where the series resistance dominates) except for the smallest diode of $250 \mu \mathrm{m} \times 250 \mu \mathrm{m}$. This could be due to a small error in the measurement of the diodes area

Table II. Structural characteristics of the GalnP single-junction solar cell used in this study.

\begin{tabular}{lcc}
\hline Layer & $\begin{array}{c}\text { Thickness } \\
(\mathrm{nm})\end{array}$ & $\begin{array}{c}\text { Doping level } \\
\left(\mathrm{cm}^{-3}\right)\end{array}$ \\
\hline Window, n:AllnP & 20 & $8 \cdot 10^{17}$ \\
Emitter, n:GalnP 2 & 150 & $4 \cdot 10^{18}$ \\
Base, p:GalnP 2 & 550 & $1 \cdot 10^{17}$ \\
BSF, p:AlGalnP & 75 & $5 \cdot 10^{17}$ \\
\hline
\end{tabular}

BSF, back surface field

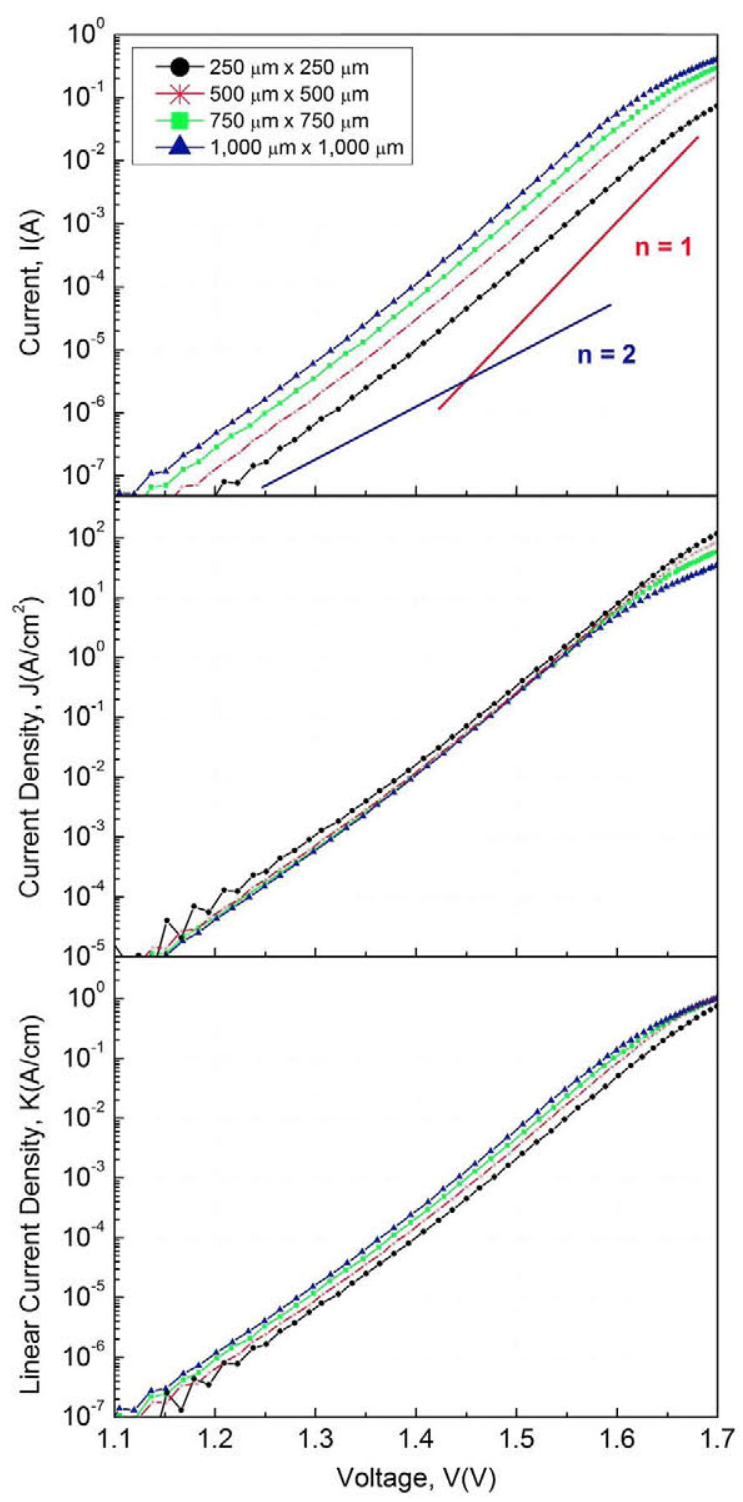

Figure 1. GalnP current versus voltage (top figure), current density versus voltage (figure in the center), and linear current density versus voltage (bottom figure) of diodes of different perimeter/area. $I-V$ curves with an ideality factor value of 1 (red line) and 2 (blue line) have also been included in the top figure.

that would have a higher impact in the smallest diodes or because the recombination at the perimeter in the smallest diodes is not completely negligible. In fact, at low voltages, even though the measurements are affected by noise, an ideality factor of 2 can be discerned. Conversely, Figure 1 shows that none of the $K-V$ curves are coincident. However, again at low voltages, the curve of the smallest diodes seems to have a tendency to overlap with the curve of diodes of $500 \mu \mathrm{m} \times 500 \mu \mathrm{m}$. Therefore, from these measurements is clear that the recombination at the perimeter in GaInP SJSCs is not a main recombination mechanism at 
least in diodes of $500 \mu \mathrm{m} \times 500 \mu \mathrm{m}$ or lager. Therefore, as a first approximation recombination at the perimeter could be neglected in commercial solar cells (which are typically larger than $500 \mu \mathrm{m} \times 500 \mu \mathrm{m}$ ). Then, once the recombination at the perimeter has been neglected in diodes of $500 \mu \mathrm{m} \times 500 \mu \mathrm{m}$ or larger, we can assert that the main current recombination at voltages higher than $1.1 \mathrm{~V}$ in our GaInP SJSCs takes place in the bulk. However, it has to be pointed out that in the study carried out by Reinhardt et al. in [5], they observed that at $1.1 \mathrm{~V}$, the recombination at the perimeter was only completely negligible in diodes as large as $2 \mathrm{~cm} \times 2 \mathrm{~cm}$.

\subsection{GaAs}

The semiconductor structure of the $\mathrm{n}^{+} / \mathrm{p}$ GaAs diodes used in this study is shown in Table III. Diodes of sizes ranging from $250 \mu \mathrm{m} \times 250 \mu \mathrm{m}\left(6.25 \cdot 10^{-4} \mathrm{~cm}^{2}\right)$ to $1 \mathrm{~cm} \times 1 \mathrm{~cm}$ have been manufactured. In Figure 2, representative current-voltage, current density-voltage, and linear current density-voltage curves are presented.

At low voltages $(\mathrm{V} \leq 0.8 \mathrm{~V})$, the recombination current of all the diodes of different sizes has an ideality factor $n=2$ (see the top of Figure 2). This recombination current is due to the recombination at the perimeter because at low voltages, the currents of the diodes of different sizes correlate with the perimeter and not with the area (Figure 2).

At moderate and high voltages $(\mathrm{V}>0.8 \mathrm{~V})$, three different behaviors are observed depending on the size of the diode:

- In the smallest diode of $250 \mu \mathrm{m} \times 250 \mu \mathrm{m}$ (P/A = 160 ), its $J-V$ curve does not overlap the $J-V$ curves at high voltages revealing that perimeter dependence extends to the entire voltage range.

- The diodes of $500 \mu \mathrm{m} \times 500 \mu \mathrm{m}, 750 \mu \mathrm{m} \times 750 \mu \mathrm{m}$, and $1000 \mu \mathrm{m} \times 1000 \mu \mathrm{m}$ at moderate voltages $(0.95 \mathrm{~V}$ $<\mathrm{V}<1.05 \mathrm{~V})$ neither the $J-V$ curves nor $K-V$ curves overlap. In order to explain this behavior, numerical simulations with Atlas Silvaco have been carried out (Figure 3). It should be noticed the excellent reproduction with the numerical model of the experimental measurements (the starts and the gray line overlap). The validity of the numerical model and a detailed explanation of the recombination at the perimeter

Table III. Semiconductor structure of the GaAs diodes studied.

\begin{tabular}{lcrr}
\hline Layer & Material & $\begin{array}{c}\text { Thickness } \\
(\mathrm{nm})\end{array}$ & \multicolumn{1}{c}{$\begin{array}{c}\text { Doping } \\
\left(\mathrm{cm}^{-3}\right)\end{array}$} \\
\hline Window & $\mathrm{Al}_{0.7} \mathrm{Ga}_{0.3} \mathrm{As}: \mathrm{Si}$ & 30 & $1 \cdot 10^{18}$ \\
Emitter & $\mathrm{GaAs}: \mathrm{Si}$ & 160 & $1.5 \cdot 10^{18}$ \\
Base & $\mathrm{GaAs}: \mathrm{Zn}$ & 3500 & $3.5 \cdot 10^{17}$ \\
BSF & $\mathrm{Al}_{0.35} \mathrm{Ga}_{0.65} \mathrm{As}: \mathrm{C}$ & 168 & $2 \cdot 10^{18}$ \\
\hline
\end{tabular}

BSF, back surface field.

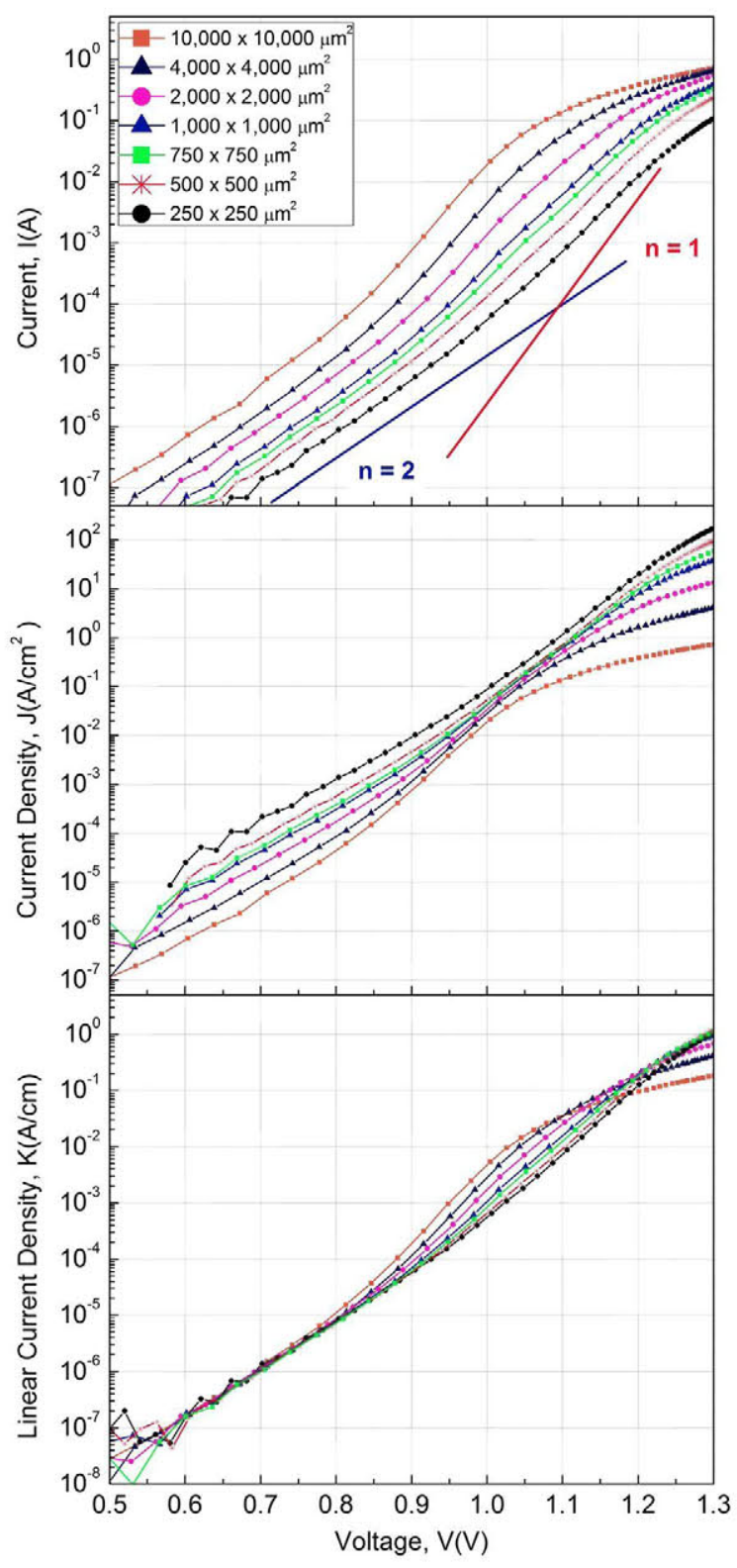

Figure 2. GaAs current versus voltage (top figure), current density versus voltage (figure in the center), and linear current density versus voltage (bottom figure) of diodes of different perimeter/area. $I-V$ curves with an ideality factor value of 1 (red line)and 2 (blue line) have also been included in the top figure.

in GaAs SJSCs can be found in reference [12]. In Figure 3, the main recombination currents that take place in the GaAs diode of $1000 \mu \mathrm{m} \times 1000 \mu \mathrm{m}$ $(\mathrm{P} / \mathrm{A}=40)$ are shown. We can deduce that at low voltages $(\mathrm{V} \leq 0.95 \mathrm{~V})$, the main recombination current is at the perimeter in the intersection with the depletion region because it has a $2 \mathrm{kT}$ behavior. However, as explained in Section 2, at higher voltages $(\mathrm{V}>0.95 \mathrm{~V})$, the recombination at the perimeter is extended towards the intersection with the neutral 
regions, and its ideality factor is reduced. In Figure 3, we observe that approximately from 0.95 to $1.05 \mathrm{~V}$, the recombination current has both the recombination at the perimeter and the recombination in the bulk as main contributions and that is why neither the $J-V$ curves nor $K-V$ curves overlap. At higher voltages ( $\mathrm{V}$ $>1.05 \mathrm{~V}$ ), the main recombination takes place in the neutral regions so the $J-V$ curves overlap up to the voltage where the curves bend because of the series resistance.

- In the larger diodes of $2 \mathrm{~mm}$ x $2 \mathrm{~mm}, 4 \mathrm{~mm} \times 4 \mathrm{~mm}$, and $1 \mathrm{~cm} \times 1 \mathrm{~cm}$, at moderate and high voltages (V $>0.8 \mathrm{~V}$ ), the $K-V$ curves are not coincident so the recombination at the perimeter is negligible. In the numerical simulations with Atlas Silvaco of a diode of $4 \mathrm{~mm} \times 4 \mathrm{~mm}(\mathrm{P} / \mathrm{A}=10)$ presented in Figure 4, we observe that the main recombination at $\mathrm{V}>1 \mathrm{~V}$ takes place in the bulk (SRH and radiative). Therefore, the $J-V$ curves should overlap but they do not because of the high impact of the series resistance.

According to the previous observations, in order to achieve the highest efficiency in concentrator GaAs SJSCs, a key parameter in the design would be the P/A of the solar cell so the recombination at the perimeter is negligible at the photogenerated current. Alternatively, smaller solar cells could be manufactured by minimizing somehow the perimeter recombination, for instance, by means of chemical or structural passivation [14-16]. For example, it has been observed experimentally and modeled with numerical simulations that a lower doping in the base implies a higher recombination at the perimeter because the surface channel created is deeper and more intense in terms of voltage barrier [12]. Therefore, in order to fabricate small GaAs solar cells without detrimental efficiency losses at high concentrations due to perimeter recombination, the semiconductor structure design should be optimized to minimize the surface channel.

Another point of interest is the deconvolution of the dark $I-V$ curve of GaAs diodes in $\mathrm{kT}$ and $2 \mathrm{kT}$ terms. In Figures 3 and 4 , we can see that at moderate voltages, the impact of the recombination at the perimeter is very different in solar cells of different sizes, and it is also very dependent on the voltage bias. Therefore, the achievement of an ideality factor and a saturation current density according to expression (6) could be misleading. However, at low voltages, we have observed a clear $2 \mathrm{kT}$ behavior in the $I-V$ curves of all the diodes (solar cells) of different sizes. Then, we can calculate the linear saturation current density of the recombination at the perimeter at low voltages according to expression (5), where $n_{P D R}=2$. The current density at low voltages with an ideality factor of 2 could be due to recombination in the bulk or recombination at the perimeter:

$J_{02} \cdot e^{(q V / 2 k T)}=J_{02 D R S R H} \cdot e^{(q V / 2 k T)}+K_{02 P} \cdot e^{(q V / 2 k T)}(P / A)$

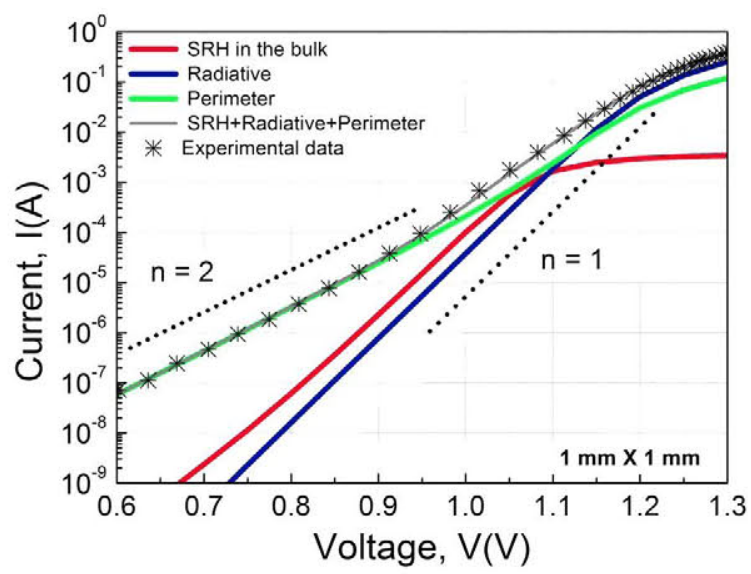

Figure 3. Experimental $I-V$ curve of the diode of $1 \mathrm{~mm} \times 1 \mathrm{~mm}$ $(P / A=40)$ (stars) and the main recombination currents obtained by numerical simulations with Atlas Silvaco (lines) [12].

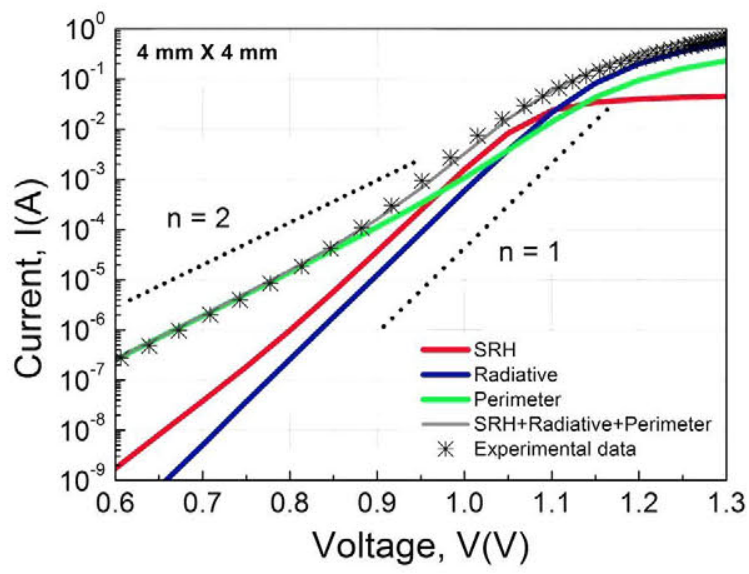

Figure 4. Experimental $I-V$ curve of the diode of $4 \mathrm{~mm} \times 4 \mathrm{~mm}$ $(P / A=10)$ (stars) and the main recombination currents obtained by numerical simulations with Atlas Silvaco (lines) [12].

where $J_{02}\left(\mathrm{~A} / \mathrm{cm}^{2}\right)$ is the saturation current density with ideality factor $n=2, J_{02 D R S R H}\left(\mathrm{~A} / \mathrm{cm}^{2}\right)$ is the saturation current density in the depletion region, $K_{02 P}(\mathrm{~A} / \mathrm{cm})$ is the linear recombination current density at the perimeter, and the rest of the parameters have their standard meaning.

Accordingly, the low voltage region $(\mathrm{V} \leq 0.8 \mathrm{~V})$ of the $I-V$ curves of the diodes of different sizes were fitted to the expression $I_{02} \cdot \mathrm{e}^{(q V / 2 k T)}$. The values of the saturation current $\mathrm{I}_{02}$ obtained from the fit were divided by their corresponding area in order to represent $J_{02}$ versus P/A as shown in Figure 5. By means of a linear fit of the data in Figure 5, the values of $J_{02 D R S R H}$ and $K_{02 P}$ are directly obtained. $K_{02 P}$ is extracted from the slope of the curve, and $J_{02 D R S R H}$ is obtained from the intercept of $J_{02}$ with $\mathrm{P} / \mathrm{A}=0$. In Figure 5, a satisfactory 


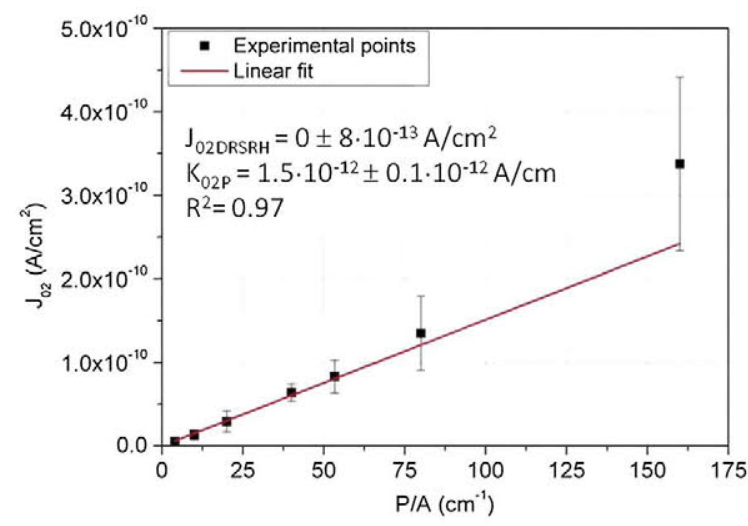

Figure 5. Saturation current density with ideality factor 2 versus perimeter-to-area ratio.

Table IV. Structure of the Ge single-junction solar cell studied.

\begin{tabular}{llrl}
\hline Layer & \multicolumn{1}{c}{ Material } & $\begin{array}{r}\text { Thickness } \\
(\mathrm{nm})\end{array}$ & $\begin{array}{l}\text { Doping } \\
\left(\mathrm{cm}^{-3}\right)\end{array}$ \\
\hline Cap & $\mathrm{Ga}(\ln )_{0.1} \mathrm{As}: \mathrm{Si}$ & 500 & $8 \cdot 10^{17}$ \\
Buffer & $\mathrm{Ga}_{0.5} \operatorname{In}_{0.5} \mathrm{P}: \mathrm{Si}$ & 1000 & $2 \cdot 10^{18}$ \\
Emitter & $\mathrm{Ge}: \mathrm{P}$ & 180 & $7 \cdot 10^{18}$ \\
Base & $\mathrm{Ge}$ & 1700 & $1 \cdot 10^{18}$ \\
\hline
\end{tabular}

fit to a linear curve is obtained. As we deduced from Figure 2 (all the $K-V$ curves overlap at low voltages), the value extracted for the recombination in the bulk of the depletion region is virtually zero. This experimental value also confirms the numerical simulation showing that the contribution of the recombination in the bulk at low voltages was negligible (Figures 3 and 4 ). With regard to the value of the linear recombination current density at the perimeter $\left(K_{02 P}\right)$, it is extracted from the slope of the linear fit, and it is $K_{02 P}=(1.5 \pm 0.1) \cdot 10^{-12} \mathrm{~A} / \mathrm{cm}$. The value obtained for the saturation current at the perimeter lies within the range of values reported in the literature for $\mathrm{p}^{+} / \mathrm{n}$ GaAs diodes that goes from $6.7 \cdot 10^{-14}$ to $1.5 \cdot 10^{-12} \mathrm{~A} / \mathrm{cm}$ [6,14,17-19].

\subsection{Ge}

In this section, we analyze the dark $I-V$ curves of Ge SJSCs with the structure presented in Table IV. The junction in the Ge SJSC has been formed by phosphorous diffusion from the GaInP buffer layer grown by pressure metal-organic vapor-phase epitaxy on the Ge substrate. We have manufactured diodes with sizes ranging from $250 \mu \mathrm{m} \times 250 \mu \mathrm{m}$ to $1000 \mu \mathrm{m} \times 1000 \mu \mathrm{m}$.

In Figure 6, typical current-voltage, current densityvoltage, and linear current density-voltage curves of the diodes manufactured are presented. Three main conclusions can be drawn:

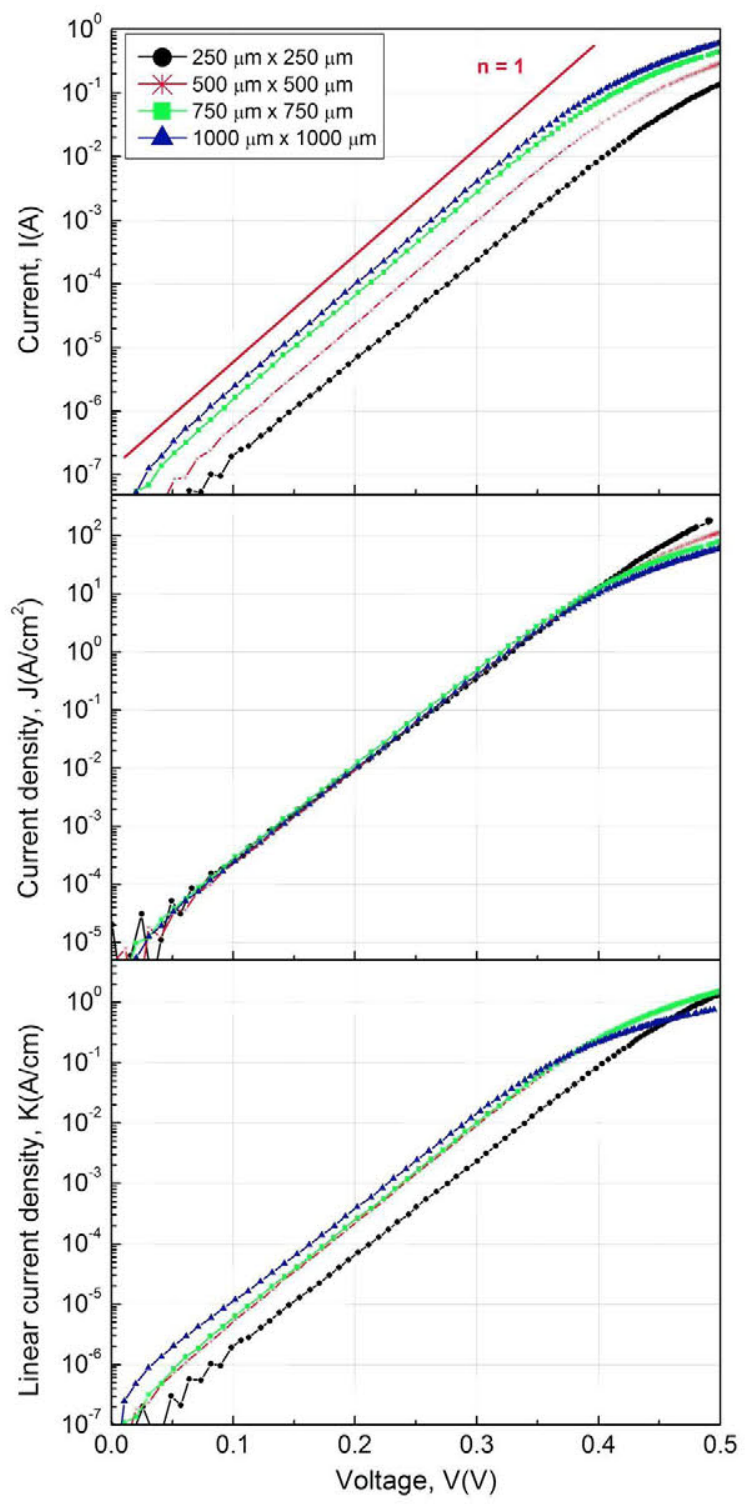

Figure 6. Ge current versus voltage (top figure), current density versus voltage (figure in the center), and linear current density versus voltage (bottom figure) of diodes of different perimeter/area. $I-V$ curves with an ideality factor value of 1 (red line) has also been included in the top figure.

1. Only one slope with an ideality factor of 1 is observed in the $I-V$ curves except for the bending at high voltages due to the series resistance.

2. The $I-V$ curve has an area dependence in the whole voltage range because all the $J-V$ curves overlap. Therefore, the recombination current with an ideality factor of 1 is due to recombination in the bulk in the neutral regions.

3. No overlap in the $K-V$ curves together with the $\mathrm{n}=1$ tendency of all curves means that the recombination 
at the perimeter even in diodes as small as $250 \mu \mathrm{m} \times$ $250 \mu \mathrm{m}$ is negligible.

\section{CONCLUSIONS}

In this paper, we have analyzed the influence of the perimeter recombination of the subcells that makeup a lattice-matched $\mathrm{GaInP} / \mathrm{GaAs} / \mathrm{Ge} 3 \mathrm{JSC}$. With this purpose, SJSCs resembling those of a 3 JSC have been grown, and diodes of different sizes have been manufactured.

In the case of GaInP SJSCs, the $I-V$ curve has an area dependence for devices of $500 \mu \mathrm{m} \times 500 \mu \mathrm{m}$ or larger. Therefore, the perimeter recombination is negligible even at low voltages and in diodes as small as $2.5 \cdot 10^{-3} \mathrm{~cm}^{2}$.

Regarding GaAs SJSCs, two regions are present in a typical dark $I-V$ curve. In the low voltage region $(\mathrm{V} \leq 0.8 \mathrm{~V})$, all the diodes with sizes ranging from $250 \mu \mathrm{m} \times 250 \mu \mathrm{m}\left(6.25 \cdot 10^{-4} \mathrm{~cm}^{2}\right)$ to $1 \mathrm{~cm}^{2}$ have an ideality factor of 2 . The origin of the ideality factor $n=2$ in all the cases is due to the perimeter recombination in the intersection with the depletion region. Therefore, the recombination at the perimeter in GaAs SJSCs is not negligible at low voltages even in solar cells as large as $1 \mathrm{~cm}^{2}$. In the high voltage region, the recombination at the perimeter in the intersection with the neutral regions is less significant in large devices where recombination in the bulk becomes dominant. However, in diodes as small as $250 \mu \mathrm{m} \times 250 \mu \mathrm{m}$, the main recombination current for the complete voltage range covered is the perimeter recombination. Finally, the value of the linear saturation current density with a $2 \mathrm{kT}$ behavior has been obtained: $K_{02 P}=1.5 \cdot 10^{-12} \pm 0.1 \cdot 10^{-12} \mathrm{~A} / \mathrm{cm}$.

In Ge SJSCs, only one region with a $\mathrm{kT}$ behavior $(\mathrm{n}=1)$ is observed in the $I-V$ curve, and it depends on the area. Therefore, the whole $I-V$ curve of the Ge subcell is dominated by recombination of carriers that are diffused into the neutral regions. The recombination at the perimeter is negligible even in the smallest diodes of size $250 \mu \mathrm{m} \times$ $250 \mu \mathrm{m}$.

\section{ACKNOWLEDGEMENTS}

The authors would like to thank J. Bautista for his continuous support. This work was supported by the European Commission under the project NGCPV 'A new generation of concentrator photovoltaic solar cells, modules and systems' with grant agreement no. 283798 . The Spanish Ministerio de Economía y Competitividad has also contributed with the projects TEC2011-28639C02-01, TEC2012-3728, IPT-2011-1441-920000, and the Comunidad de Madrid under the NUMANCIA II program (S2009/ENE1477). The work has been also supported by the European Commission and the Fundación Madri+d within the ERA-NET MATERA+ (FP7) through the project NANOCDTESOLAR.

\section{REFERENCES}

1. Algora C, Rey-Stolle I. The interest and potential of ultra-high concentration. In Next Generation of Photovoltaics, Vol. 165 of Springer Series in Optical Sciences, Cristóbal López AB, Martí Vega A, Luque López A (eds). Springer Berlin/Heidelberg, 2012; 23-60. http://dx.doi.org/10.1007/978-3-642-233692_2.

2. http://www.semiconductor-today.com/news ${ }_{i}$ tems $/ 2013 /$ JUN/SHARP $190613 . \mathrm{html}$ [Accessed on 19 June 2013].

3. Furman B, Menard E, Gray A, Meitl M, Bonafede S, Kneeburg D, Ghosal K, Bukovnik R, Wagner W, Gabriel J, Seel S, Burroughs S. A high concentration photovoltaic module utilizing micro-transfer printing and surface mount technology, In 2010 35th IEEE Photovoltaic Specialists Conference (PVSC), Honolulu, Hawaii, 2010; 000475-000480. DOI: 10.1109/PVSC. 2010.5616766.

4. Espinet P, Algora C, González J, Núñez N, Vázquez M. Degradation mechanism analysis in temperature stress tests on III-V ultra-high concentrator solar cells using a 3D distributed model. Microelectronics Reliability 2010; 50(9-11): 1875-1879, 21st European Symposium on the Reliability of Electron Devices, Failure Physics and Analysis. DOI: 10.1016/ j.microrel.2010.07.128. http://www.sciencedirect.com/ science/article/pii/S0026271410004014 [Accessed on 1 September 2010]

5. Reinhardt KC, Yeo YK, Hengehold RL. Junction characteristics of $\mathrm{Ga}_{0.5} \mathrm{In}_{0.5} \mathrm{P} \mathrm{n}{ }^{+} \mathrm{p}$ diodes and solar cells. Joumal of Applied Physics 1995; 77(11): 5763-5772. DOI:10.1063/1.359221

6. DeMoulin P, Tobin S, Lundstrom M, Carpenter M, Melloch M. Influence of perimeter recombination on high-efficiency GaAs p/n heteroface solar cells. IEEE Electron Device Letters 1988; 9(8): 368-370. DOI:10.1109/55.746

7. Belghachi A, Khelifi S. Modelling of the perimeter recombination effect in GaAs-based micro-solar cell. Solar Energy Materials and Solar Cells 2006; 90(1): 1-14. DOI:10.1016/j.solmat.2005.01.009. http:/www.sciencedirect.com/science/article/pii/ S0927024805000309 [Accessed on 4 March 2005]

8. Eisler C, Sheldon M, Atwater H. Enhanced performance of small GaAs solar cells via edge and surface passivation with trioctylphosphine sulfide, In 2012 38th IEEE Photovoltaic Specialists Conference (PVSC), Austin, Texas, 2012; 000937-000940. DOI: 10.1109/PVSC.2012.6317756.

9. Kurtz S. Opportunities and challenges for development of mature concentrating photovoltaic power industry. 
Tech. rep., National Renewable Energy Laboratory, NREL, 2012.

10. Luque A, Hegedus S (eds.) Handbook of Photovoltaic Science and Engineering. Wiley: Chichester, 2003.

11. Sze SM. Physics of Semiconductor Devices, 2nd Edition. Wiley: New York, 1981.

12. Ochoa M, Algora C, Espinet-González P, Garcia I. 3-D modeling of perimeter recombination in GaAs diodes and its influence on concentrator solar cells. Solar Energy Materials and Solar Cells Part A 2014; 120: $48-58$

13. Dodd P, Stellwag T, Melloch M, Lundstrom M. Surface and perimeter recombination in GaAs diodes: an experimental and theoretical investigation. IEEE Transactions on Electron Devices 1991; 38(6): 1253-1261. DOI: 10.1109/16.81614

14. Stellwag TB, Melloch MR, Lundstrom MS, Carpenter MS, Pierret RF. Orientation-dependent perimeter recombination in GaAs diodes. Applied Physics Letters 1990; 56(17): 1658, http://search.ebscohost.com/ login. aspx ?direct $=$ true $\& \mathrm{db}=$ aph $\& \mathrm{AN}=9833985 \&$ site $=$ ehost-live \&scope $=$ site [Accessed on 9 February 1990].

15. Carpenter MS, Melloch MR, Lundstrom MS, Tobin SP. Effects of $\mathrm{Na}_{2} \mathrm{~S}$ and $\left(\mathrm{NH}_{4}\right)_{2} \mathrm{~S}$ edge passivation treatments on the dark currentvoltage characteristics of GaAs pn diodes. Applied Physics Letters 1988; 52(25): 2157-2159. DOI: $10.1063 / 1.99563$

16. Sheldon MT, Eisler CN, Atwater HA. GaAs passivation with trioctylphosphine sulfide for enhanced solar cell efficiency and durability. Advanced Energy Materials 2012; 2(3): 339-344. DOI: 10.1002/aenm. 201100666

17. Díaz V, Algora C. Effects of the size and shape of GaAs solar cells on recombination losses, In 3 ra Conferencia Dispositivos Electrónicos, Granada, 2001; 289-292.

18. Henry CH, Logan RA, Merritt FR. The effect of surface recombination on current in $\mathrm{Al}_{x} \mathrm{Ga}_{1-x}$ As heterojunctions. Journal of Applied Physics 1978; 49(6): 3530-3542. DOI: 10.1063/1.325265

19. Tobin S, Vernon S, Bajgar C, Wojtczuk S, Melloch M, Keshavarzi A, Stellwag T, Venkatensan S, Lundstrom M, Emery K. Assessment of MOCVD- and MBE-growth GaAs for high-efficiency solar cell applications. IEEE Transactions on Electron Devices 1990; 37(2): 469-477. DOI: $10.1109 /$ 16.46385 